\title{
TWO EXTRAPOLATION THEOREMS FOR RELATED WEIGHTS AND APPLICATIONS
}

\author{
M. LORENTE AND M. S. RIVEROS
}

\begin{abstract}
In this paper we prove two extrapolation theorems for related weights. The theorems proved by C. Segovia and J. L. Torrea in [C. Segovia and J. L. Torrea, Weighted inequalities for commutators of fractional and singular integrals, Publ. Mat. 35, (1991), 209-235] are adapted for one-sided weights. We apply these extrapolation theorems to improve weighted inequalities for commutators (with symbol $b$ depending on the related weights) of several one-sided operators such as the Weyl and the Riemann-Liouville fractional integrals, or one-sided maximal operators given by the convolution with a smooth function. We also characterize the symbols $b$ for which the commutators of these one-sided operators are bounded.
\end{abstract}

Mathematics subject classification (2000): 42B20.

Key words and phrases: extrapolation, one-sided weights, one-sided operators, commutators.

\section{REFERENCES}

[1] H. Aimar, L. Forzani AND F. J. MARtín-ReYes, On weighted inequalities for one-sided singular integrals, Proc. Amer. Math. Soc., 125, (1997), 2057-2064.

[2] K. F. ANDERSEn, E. T. SAWYER, Weighted norm inequalities for the Riemann-Liouville and Weyl fractional integral operators, Trans. Amer. Math. Soc., 308, (2) (1988), 547-558.

[3] D. Cruz Uribe, J. M. Martell AND C. PÉREZ, Extrapolation from $A_{\infty}$ weights and applications, J. Funct. Anal., 213, (2) (2004), 412-439.

[4] J. García Cuerva, J. L. Rubio De Francia, Weighted norm inequalities and related topics, NorthHolland , 1985.

[5] E. Harboure, R. A. Macías And C. Segovia, Extrapolation results for classes of weights, Amer. Jour. Math. 110, (1988), 383-397.

[6] E. Harboure, R. A. Macías, C. Segovia, An extrapolation theorem for pairs of weights, Cuadernos de Matemática y Mecánica , (1987) 2-87.

[7] M. LORENTE, M. S. RiveroS, Two weight norm inequalities for commutators of one-sided singular integrals and the one-sided discrete square function, Jour. Aust. Math. Soc., 79, (2005), 77-94.

[8] M. LORENTE, M. S. RIVEROS, Weights for commutators of the one-sided discrete square function, the Weyl fractional integral and other one-sided operators, Proc. Roy. Soc. Edinburgh, 135, A (2005), $845-862$.

[9] R. MACías, M. S. Riveros, One-sided extrapolation at infinity and singular integrals, Proc. Roy. Soc. Edinburgh Sect. A, 130, (2000), 1081-1102.

[10] F. J. MARTÍN-REYES, New proofs of weighted inequalities for the one-sided Hardy-Littlewood maximal functions, Proc. Amer. Math. Soc., 117, (1993), 691-698.

[11] F.J. MARTÍN-Reyes, P. ORTEGA AND A. DE LA TORRE, Weighted inequalities for one-sided maximal functions, Trans. Amer. Math. Soc., 319 (2), (1990), 517-534.

[12] F. J. Martín-Reyes, L. Pick And A. De la Torre, $A_{\infty}^{+}$condition, Canad. J. Math., 45, (1993), 1231-1244.

[13] F. J. Martín-Reyes, A. DE La Torre, One-sided BMO spaces, J. London Math. Soc. 2, 49, (1994), $529-542$ 
[14] B. Muckenhoupt, Weighted norm inequalities for classical operators, Proc. Sympos. Pure Math. Amer. Math. Soc., Providence, R.I. 35, (1) (1979), 69-83.

[15] M. S. Riveros, A. DE LA TORRE, On the best ranges for $A_{p}^{+}$and $R H_{r}^{+}$, Czechoslovak Math. J. 51, (126) (2001), 285-301.

[16] J. L. RUBio DE Francia, Factorization Theory and $A_{p}$ Weights, Amer. Jour. Math., 106, (1984), 533-547.

[17] E. T. SAWYER, Weighted inequalities for the one-sided Hardy-Littlewood maximal functions, Trans. Amer. Math. Soc., 297, (1986), 53-61.

[18] C. SEgOVIA, J. L. TORREA, Weighted inequalities for commutators of fractional and singular integrals, Publ. Mat., 35, (1991), 209-235.

[19] C. Segovia, J. L. ToRreA, Vector-valued commutators and applications, Indiana Univ. Math. J., 38, (4) , (1989), 959-971.

[20] C. Segovia, J. L. Torrea, Extrapolation for pairs of related weights, Lect. notes in pure and appl. math., 122, (1990), 331-345.

[21] J. STRÖMBERG, A. TORCHINSKY , Weighted Hardy spaces, Lecture Notes in Math. (Springer-Verlag), 1989. 